\title{
Evidência de Validade Convergente entre Instrumentos de Avaliação da Consciência Fonológica
}

\author{
Adriana Cristina Boulhoça Suehiro \\ Universidade Federal do Recôncavo da Bahia \\ Santo Antônio de Jesus, BA, Brasil \\ Acácia Aparecida Angeli dos Santos \\ Universidade São Francisco \\ Itatiba, SP, Brasil
}

\begin{abstract}
RESUMO
O presente estudo buscou por evidência de validade convergente entre instrumentos de avaliação da consciência fonológica. Participaram 221 crianças, ambos os sexos, entre 6 e 12 anos $(M=8,53 ; D P=1,40)$ de segundo ao quinto ano do Ensino Fundamental de escola pública do interior de São Paulo. Os participantes foram submetidos, individualmente, ao Roteiro de Avaliação da Consciência Fonológica (RACF) e à Prova de Consciência Fonológica por Produção Oral (PCFO). Foi identificada uma correlação positiva e moderada $(r=0,65)$ entre os instrumentos, indicando que o RACF pode ser usado para avaliar o mesmo construto. Considerando que é um instrumento de rastreio poderá fornecer uma avaliação rápida e de baixo custo para ser usada nessa etapa da escolarização.
\end{abstract}

Palavras-chave: Validade; parâmetros psicométricos; consciência fonológica.

\begin{abstract}
Convergent Validity Evidence between Instruments for Assessment of Phonological Awareness

The present study searched for convergent validity evidence between instruments for assessment of phonological awareness. The participants consisted of 221 children, both sexes, with ages ranging from 6 to 12 years $(M=8.53$, $S D=1.40$ ) from first to fourth grade elementary public school in São Paulo. The instruments, applied individually, were the Roteiro de Avaliação da Consciência Fonológica (RACF) and the Prova de Consciência Fonológica por Produção Oral (PCFO). A positive and moderate correlation $(r=.65)$ was found between the instruments, indicating that the RACF can be used to assess the same construct. Considering that it is a screening tool may provide a quick assessment and cost-effective to be used in this stage of schooling.
\end{abstract}

Keywords: Validity; psychometric properties; phonological awareness.

\section{RESUMEN}

La Validez Convergente entre los Instrumentos de Evaluación de la Conciencia Fonológica

Este estudio buscó pruebas de validez convergente entre las herramientas de evaluación de la conciencia fonológica. Participaron 221 niños de ambos sexos, entre 6 y 12 años $(M=8,53, S D=1,40)$ del segundo a quinto grado de escuela pública de São Paulo de la enseñanza primaria. Los participantes fueron evaluados de forma individual, el Roteiro de Avaliação da Consciência Fonológica (RACF) y Prova de Consciência Fonológica por Produção Oral (PCFO). Y se encontró correlación positiva moderada $(r=0,65)$ entre los instrumentos que indican que RACF puede ser utilizado para evaluar la misma construcción. Teniendo en cuenta que es una herramienta de detección pueden proporcionar una evaluación rápida y rentable a utilizar en esta etapa de la escolaridad.

Palabras clave: Validez; parámetros psicométricos; conciencia fonológica. 
O processamento fonológico envolve um conjunto de operações mentais de processamento de informação que se baseiam na estrutura fonológica da linguagem oral. Há três tipos de processamento fonológico relacionados às habilidades de leitura e escrita, a saber, o acesso ao léxico mental, a memória de trabalho fonológica e a consciência fonológica, sendo esta última referente ao construto, cujas medidas serão aqui focalizadas (Capovilla, Dias, \& Montiel, 2007; Justi, Roazzi, \& Justi, 2014; Torgesen, Wagner, \& Rashotte, 1994).

Denomina-se consciência fonológica a habilidade metalinguística de tomada de consciência das características formais fonológicas ou da estrutura sonora da linguagem. Refere-se também à habilidade de manipular intencionalmente a estrutura sonora das palavras desde a substituição de um determinado som até a sua segmentação em unidades menores (Corrêa \& Cardoso-Martins, 2012; Mota \& Santos, 2009; Mota et al., 2012; Nascimento, 2006; Novaes, Mishima, \& Santos, 2013).

São três as sub-habilidades que a consciência fonológica envolve, quais sejam, rimas/aliterações; consciência silábica e consciência fonêmica (Barrera \& Maluf, 2003; Godoy, Fortunato, \& Paiano, 2014). A habilidade de análise silábica se desenvolve antes da manipulação de fonemas. Uma explicação para o fato de elas serem desenvolvidas mais precocemente é a de que a extração intencional das sílabas, unidades discretas da fala, requer um esforço analítico menor. Por sua vez, a identificação dos fonemas individuais pressupõe o recebimento de instruções explícitas sobre as regras da escrita alfabética (Hagen, Miranda, \& Mota, 2010; Mota \& Guimarães, 2011; Pestun, Osmote, Barreto, \& Matsuo, 2010).

As habilidades para detecção da rima (som final da palavra) e aliteração (som inicial da palavra) são especialmente importantes para este estudo visto que o instrumento aqui utilizado avalia a habilidade de a criança identificar, além da rima e aliteração, o fonema intermediário de palavras. Essas sub-habilidades que compõem a consciência fonológica têm sido focalizadas por diversos pesquisadores tanto em línguas estrangeiras (Bradley \& Bryant, 1983; Goswami \& Bryant, 1997; Phillips, Clancy-Manchetti, \& Lonigan, 2008) como no português (Cardoso-Martins \& Frith, 1999; Cárnio \& Santos, 2005; Mousinho \& Correa, 2009; Pestun et al., 2010; Suehiro \& Santos, 2011).

Roazzi e Dowker (1989), ao discutirem a consciência fonológica em crianças pequenas e sua relação com o uso de rimas e aliterações em poesias, concluíram que a segmentação parcial é mais fácil que a completa e que a rima é mais fácil que a aliteração.
Ao lado disso, ressaltaram que a identificação da rima e aliteração ajuda a criança a se interessar mais por aspectos da linguagem em geral e não só pelos sons em si, o que pode ser importante para a leitura. Os autores ressaltam que o desempenho em tarefas de consciência fonológica tende a melhorar com a idade.

Em contrapartida, os resultados da pesquisa desenvolvida por Cardoso-Martins (1991) indicaram que a habilidade para classificar palavras quanto à rima ou o som intermediário foi menos frequente do que a identificação do som inicial, que implica a habilidade de aliteração. Este achado foi similar, tanto para as crianças que estavam sendo alfabetizadas pelo método silábico, quanto para as que estavam sendo instruídas pelo método fônico. Esses resultados são contraditórios em relação aos obtidos por Roazzi e Dowker (1989) e deixam clara a necessidade de mais estudos sobre a temática. Além disso, apontam para a importância do procedimento de avaliação, visto que eventuais diferenças poderiam ser atribuídas a ele.

Em estudo posterior, Cardoso-Martins e Frith (1999) avaliaram indivíduos com Síndrome de Down alfabetizados pelo método fônico e verificaram que estes também obtiveram escores inferiores em tarefas de identificação da rima, quando comparados aos de identificação do fonema. Diante de tais resultados, as autoras hipotetizaram que o procedimento utilizado para identificar a rima teria gerado esse resultado inesperado. De acordo com elas, a tarefa com a rima foi provavelmente mais difícil do que a de detecção do fonema, na qual o fonema-alvo era claramente explicitado. Por fim, destacaram a necessidade de se considerar que os indivíduos avaliados estavam sendo alfabetizados pelo método fônico, o que mostra que eles, mesmo que de maneira ainda incipiente, já apresentavam a habilidade de prestar atenção aos sons da fala.

Do mesmo modo, Barrera e Maluf(2003) obtiveram resultados diferentes aos do estudo de Roazzi e Dowker (1989). As autoras constataram que, entre as crianças de primeira série do ensino fundamental focalizadas, as provas que avaliavam a habilidade de aliteração foram mais fáceis em comparação com as que avaliavam a rima.

Tanto no Brasil, como no exterior, resultados de pesquisas têm mostrado que a habilidade para detectar rima e aliteração é preditora do progresso na aquisição da leitura e escrita (Cardoso-Martins, 1991; Hagen, Miranda \& Mota, 2010; Kim, 2009; Landgraf et al., 2012; Mota \& Guimarães, 2011). De acordo com Goswami e Bryant (1997), por exemplo, a capacidade de perceber semelhanças sonoras no início ou no final das palavras permite à criança fazer 
conexões entre os grafemas e os fonemas que eles representam, favorecendo assim a generalização dessas relações.

Dessa forma, a consciência fonológica tem sido reconhecida por pesquisadores como um componente essencial no processo de desenvolvimento da leitura e da escrita (Babayigit \& Stainthorp, 2011; Capovilla \& Capovilla, 2002; Cardoso-Martins, 1991; Monteiro \& Soares, 2014; Pestun et al., 2010; Suehiro \& Santos, 2011; Yopp, 1988). Independentemente do peso dado ao papel da consciência fonológica durante o processo de aprendizagem, um dos pontos críticos de sua avaliação tem sido a operacionalização do construto (Gough, Larson, \& Yopp, 1995; Yopp, 1988). Para autores como Correa (2001) e Capovilla et al. (2007) ela deve ser considerada como um conjunto de habilidades que, conforme mencionado, varia em ordem de aquisição.

No entanto, essa maneira de operacionalizar e conceber o construto carrega consigo uma outra questão relevante e de grande impacto sobre sua avaliação, a saber, a variação dos requisitos cognitivos exigidos para cada uma de suas tarefas e sua dificuldade (Paula, Mota, \& Keske-Soares, 2005). Sob essa perspectiva, é possível que uma criança seja capaz de realizar com êxito uma tarefa de consciência fonológica que envolva a manipulação silábica e fracasse em outra, como por exemplo, a transposição silábica ou fonêmica, dependendo do grau de dificuldade que essas tarefas apresentem (Capovilla et al., 2007).

No Brasil, um dos instrumentos com evidências de validade para a avaliação da consciência fonológica é a Prova de Consciência Fonológica por Produção Oral (PCFO), desenvolvida por Capovilla e Capovilla (1998). Dentre os estudos realizados com a prova, a maioria se dedicou à aplicação de treinos de consciência fonológica e de correspondências grafo-fonêmicas e, portanto, à intervenção. Os resultados têm apontado para o valor do treino em consciência fonológica, associado ao ensino das correspondências grafofonêmicas. Há indicações de que, independentemente do nível socioeconômico das crianças avaliadas, o treino dessa habilidade aumenta significativamente o desempenho em leitura e escrita (Bernardino Jr. et al., 2006; Cunha \& Capellini, 2009; Dias \& Bigheti, 2009; Fukuda \& Capellini, 2012; Justi \& Roazzi, 2012). Os mesmos ganhos têm sido relatados em estudos estrangeiros que empregaram outros instrumentos e procedimentos (Pedro, Oliveira, Lousada, \& Couto, 2014; Shaywitz, 2006).

O estudo de Capovilla e Capovilla (1998) contou com 175 crianças entre 3 e 9 anos, ambos os sexos, de pré (1, 2 e 3 ) a segunda série do primeiro grau (que atualmente seria o terceiro ano do Ensino Fundamental), de uma escola particular de uma cidade do interior do estado de São Paulo. Os resultados evidenciaram que as crianças de segunda série alcançaram escores mais elevados no geral e por subteste. Ao lado disso, os desempenhos em todos os subtestes que envolviam sílabas foram superiores aos que focalizavam fonemas, sendo que os escores médios mais altos foram observados para 'sintese, segmentação, manipulação silábica' e 'aliteração' e os mais baixos para 'rima', 'síntese, segmentação e manipulação fonêmica', respectivamente. Os resultados deste estudo e de outros subsequentes, que usaram o PCFO, conferiram à prova, evidências de validade para a avaliação da consciência fonológica em crianças de pré a terceira série (atuais $1 \stackrel{\mathrm{O}}{ }$ a 4ㅇaㅇ (Pedras, Geraldo, \& Crenitte, 2006; Pestun, 2005; Salgado \& Capellini, 2004).

Outro instrumento com evidências de validade para a avaliação da consciência fonológica de crianças brasileiras de pré-escola (atual $1 \stackrel{\mathrm{O}}{\mathrm{ano}}$ ) e para o qual pretende-se trazer novas evidências de validade para o uso com crianças de ensino fundamental, é o Roteiro de Avaliação da Consciência Fonológica (RACF), desenvolvido por Santos (1996). O roteiro é um instrumento de fácil aplicação e correção, visto que é composto por um conjunto de quinze itens construídos para a avaliação do som ou fonema inicial, final e o intermediário das palavras, correspondentes à rima e à aliteração na PCFO. Considerando-se que essas são as habilidades que funcionam como preditoras do progresso em leitura e escrita os resultados obtidos com o RACF poderão fornecer indicativos de possíveis dificuldades para o reconhecimento de sons das palavras, que é uma habilidade frequentemente exigida das crianças ao longo do processo de aprendizagem da leitura e da escrita.

O instrumento foi empregado por Antoniazzi, Suehiro e Santos (2005) em uma amostra de 45 crianças, ambos os sexos, ingressantes na $1^{a} \underline{a}$ série do ensino fundamental (atual $2 \mathrm{O}$ ano) a fim de identificar o nível de consciência fonológica que apresentavam. Os resultados da pesquisa mostraram que o reconhecimento do som do meio ou som intermediário foi o que suscitou maior dificuldade nas crianças avaliadas e que o reconhecimento do som inicial foi o mais fácil, sendo o desempenho nas tarefas independente da variável sexo. As autoras verificaram, ainda, que as 15 crianças que haviam sido indicadas pela escola para um serviço de atendimento psicopedagógico, em função de suas dificuldades no processo de alfabetização, apresentaram desempenhos significativamente inferiores às demais, o que forneceu evidências de validade de critério.

Por sua vez, Suehiro e Santos (2011) investigaram evidências de validade de critério pela comparação 
entre as séries em crianças da $1^{\underline{a}}$ a $4^{\mathrm{a}}$ série (atuais $2^{\mathrm{O}}$ a $4^{\mathrm{O}}$ ano) que individualmente responderam ao Roteiro de Avaliação da Consciência Fonológica (RACF). O resultado permitiu acumular mais uma evidência de validade de critério, visto que os escores aumentaram significativamente, agrupando os alunos por etapa escolar, a saber, os da primeira série num conjunto independente, os da segunda e terceira que ficaram em um único conjunto e os da $4^{\mathrm{a}}$ série em um agrupamento específico. Tal como no estudo de 2005, as pontuações médias de meninos e meninas não diferiram significativamente.

Considerando a importância da consciência fonológica no processo de alfabetização, bem como a necessidade de instrumentos pautados em princípios científicos para a sua avaliação, o presente estudo buscou por evidência de validade convergente entre o Roteiro de Avaliação da Consciência Fonológica (RACF), tendo como referência a Prova de Consciência Fonológica por produção Oral (PCFO). A hipótese é a de que haja convergência entre os instrumentos e de que o RACF seja, portanto, uma boa medida de rastreio (screening), visto possuir apenas 15 itens, que permita uma sondagem prévia e rápida para identificar eventuais dificuldades relativas a essa habilidade metalinguística.

\section{MÉTODO}

\section{Participantes}

Participaram deste estudo 221 crianças, ambos os sexos, entre 6 e 12 anos $(M=8,53 ; D P=1,40)$ de primeira a quarta séries (atuais segundo ao quinto ano) do Ensino Fundamental de uma escola pública do interior de São Paulo. A maioria dos estudantes era do sexo masculino $(n=120 ; 54,3 \%)$, sendo que $56(25,3 \%)$ estudantes frequentavam a primeira série, $54(24,4 \%)$ a segunda, $55(24,9 \%)$ a terceira e $56(25,3 \%)$ a quarta série.

\section{Instrumentos}

Questões de identificação-Os sujeitos informaram, na mesma folha do Roteiro de Avaliação da Consciência Fonológica (RACF), os seguintes aspectos: nome, idade, sexo e série a qual pertencem.

Roteiro de Avaliação da Consciência Fonológica (RACF) - (Santos, 1996) - Trata-se de um teste de rastreio (screening) e consiste de três séries de itens, cada uma com cinco itens e dois exemplos, que visam avaliar a dificuldade na identificação do fonema ou 'Som inicial', 'final' e o 'do meio' das palavras. Cada item é composto de uma palavra modelo e outras três, para alternativas de resposta. Foi atribuído um ponto para cada acerto e zero para erro, sendo a pontuação máxima possível 15. Como o RACF ainda não dispõe de normas que possibilitem um ponto de corte, a referência para a interpretação dos seus resultados é o ponto médio do instrumento que, considerando os 15 pontos possíveis, é 7,5.

$\mathrm{O}$ instrumento apresentou evidência de validade experimental (Urbina, 2007), com base em estudo realizado com 55 crianças (Média de idade: 6a2m), que não apresentavam nenhuma alteração nos padrões de desenvolvimento, matriculadas na pré-escola de duas escolas públicas e de duas escolas particulares. Após ter sido usado no pré e no pós-teste imediato, os resultados indicaram que houve efeitos positivos e significativos nos escores, que foram significativamente mais elevados após o treino, que envolveu a realização de tarefas variadas de consciência fonológica. Foram identificados, também, efeitos em médio prazo mantidos em ambos os grupos experimentais (escola pública $x$ particular), quando o roteiro foi aplicado como pós-teste atrasado.

Prova de Consciência Fonológica por produção Oral (PCFO) - (Capovilla \& Capovilla, 1998; Capovilla et al., 1998) avalia a habilidade das crianças de manipular os sons da fala, expressando oralmente o resultado dessa manipulação. A PCFO é composta por dez subtestes, sendo cada um deles composto por dois itens de treino e quatro itens de teste. Os subtestes são: Síntese Silábica, Síntese Fonêmica, Julgamento de Rima, Julgamento de Aliteração, Segmentação Silábica, Segmentação Fonêmica, Manipulação Silábica, Manipulação Fonêmica, Transposição Silábica e Transposição Fonêmica. O resultado das crianças na PCFO é apresentado como escore ou frequência de acertos, sendo o máximo possível de 40 acertos. Semelhantemente ao RACF, os resultados no PCFO possuem como parâmetro para interpretação dos resultados o ponto médio do instrumento, ou seja, 20 pontos.

Conforme descrito em Capovilla et al. (1998), o estudo de validade realizado com base numa amostra de 175 alunos da pré-escola $(1,2$ e 3$)$ à segunda série (atualmente de $1^{\mathrm{o}}$ a $3^{\mathrm{o}}$ ano) revelou que o escore específico em cada um dos dez subtestes foi função direta do nível escolar e da idade das crianças. Houve ainda correlação entre cada subteste separadamente e os desempenhos de leitura em voz alta e de escrita sob ditado para as crianças a partir do pré 3. Não houve correlação entre o desempenho em leitura e em ditado, de um lado, e os desempenhos nos subtestes de síntese silábica, segmentação silábica e rima. Isso porque, de acordo com os autores, tais subtestes são os mais fáceis da PCFO e, portanto, discriminaram melhor os desempenhos de crianças mais jovens, entre o pré 1 e pré 2 . Assim, os escores específicos em cada subteste foram considerados válidos para discriminar 
entre diferentes níveis escolares e idades, e estão relacionados a habilidades de leitura e escrita. Quanto à fidedignidade da prova, na avaliação teste e reteste, os índices foram bons tanto para o escore geral na PCFO (Pearson $r=0,90 ; 0,89 ; 0,80$ em retestes após seis, oito e 17 meses, respectivamente, todos com $p<0,001$ ) quanto para seus subtestes ( $r$ variando de 0,55 a 0,83 , com $p<0,001$ para todos os subtestes, exceto para Síntese e Segmentação Silábicas).

\section{Procedimento}

Após a autorização das instituições focalizadas e a aprovação do Comitê de Ética, em horário de aula previamente cedido pelo professor, os instrumentos foram aplicados individualmente nas crianças, cujos pais assinaram o Termo de Consentimento Livre e Esclarecido. Para a coleta de dados utilizou-se, em média, 25 minutos para cada criança, tendo havido o auxílio de doze estudantes de psicologia (graduação e pós) treinados para essa tarefa. Os dados coletados foram armazenados em planilha eletrônica (Microsoft Excel $^{\circledR}$ ) e analisados posteriormente com o pacote estatístico SPSS 21.0 (SPSS Inc.).

\section{RESULTADOS}

Os resultados foram analisados considerando-se o objetivo proposto. A Tabela 1 traz as estatísticas descritivas das pontuações obtidas pelos participantes do estudo no Roteiro de Avaliação da Consciência Fonológica (RACF).

TABELA 1

Estatísticas Descritivas do Desempenho das Crianças Avaliadas no Roteiro de Avaliação da Consciência Fonológica $(R A C F)(N=221)$

\begin{tabular}{lcccc}
\hline \multicolumn{1}{c}{ Instrumento } & Mínimo & Máximo & Média & $D P$ \\
\hline RACF - Som inicial & 1 & 5 & 4,55 & 0,74 \\
RACF - Som final & 0 & 5 & 3,63 & 1,29 \\
RACF - Som do meio & 0 & 5 & 3,05 & 1,36 \\
RACF - Total & 4 & 15 & 11,23 & 2,60 \\
\hline
\end{tabular}

Os resultados do RACF indicaram que as crianças apresentaram escores mais elevados no 'Som inicial' e no 'Som final' das palavras, respectivamente. No entanto, as médias globais obtidas ficaram abaixo da pontuação média prevista pelo instrumento, ou seja 7,5 acertos.

Os achados referentes à Prova de Consciência Fonológica por Produção Oral (PCFO) estão dispostos na Tabela 2. Vale observar que a pontuação poderia variar de 0 a 40 pontos.

\section{TABELA 2}

Estatísticas descritivas do desempenho das crianças avaliadas na Prova de Consciência Fonológica por Produção Oral (PCFO) $(\mathrm{N}=221)$

\begin{tabular}{lcccc}
\hline \multicolumn{1}{c}{ Instrumento } & Mínimo & Máximo & Média & DP \\
\hline PCFO - Síntese Silábica & 0 & 4 & 3,91 & 0,48 \\
PCFO - Síntese Fonêmica & 0 & 4 & 2,19 & 1,27 \\
PCFO - Rima & 0 & 4 & 3,36 & 0,95 \\
PCFO - Aliteração & 0 & 4 & 3,47 & 0,90 \\
PCFO - Segmentação Silábica & 0 & 4 & 3,88 & 0,55 \\
PCFO - Segmentação Fonêmica & 0 & 4 & 1,13 & 1,38 \\
PCFO - Manipulação Silábica & 0 & 4 & 3,32 & 1,09 \\
PCFO - Manipulação Fonêmica & 0 & 4 & 3,05 & 1,26 \\
PCFO - Transposição Silábica & 0 & 4 & 3,18 & 1,27 \\
PCFO - Transposição Fonêmica & 0 & 4 & 1,18 & 1,42 \\
PCFO - Total & 9 & 40 & 28,66 & 6,75 \\
\hline
\end{tabular}

No PCFO as crianças obtiveram uma média de 28,66 acertos $(D P=6,75)$, com uma pontuação mínima de 9 e máxima de 40 pontos. A média global ficou acima da que seria possível obter no instrumento, que seria de 20 pontos.

No que se refere aos subtestes que compõem a prova, observou-se que, por um lado, as pontuações médias obtidas em 'Síntese Silábica', 'Segmentação Silábica' e 'Aliteração' foram superiores às demais. Por outro lado, observou-se que os piores desempenhos ocorreram em 'Síntese Fonêmica', 'Transposição Fonêmica' e 'Segmentação Fonêmica', respectivamente. Os participantes avaliados apresentaram mais dificuldades na detecção da 'Rima' do que da 'Aliteração', tendo em vista que a pontuação média na primeira foi menor quando comparada à segunda.

Para se verificar se os instrumentos de consciência fonológica focalizados mediam, de fato, o mesmo construto e em que proporção isso ocorria, recorreuse à prova de Correlação de Spearman, visto que a hipótese de normalidade dos dados foi recusada para ambos os instrumentos (Kolmogorov-Smirnov $\mathrm{Z}=1,90 ; \mathrm{p}<0,001$ para o RACF e Kolmogorov-Smirnov $\mathrm{Z}=1,48 ; \mathrm{p}<0,05$ para a $\mathrm{PCFO}$ ). Essas correlações podem ser visualizadas na Tabela 3 .

Como pode ser observado na tabela, três dos 44 índices de correlação não foram estatisticamente significativos. Os resultados evidenciaram, de forma geral, uma correlação positiva e moderada entre os instrumentos focalizados, o que indica que os desempenhos em ambos testes de consciência fonológica têm uma parcela de mais de $40 \%$ de variância compartilhada. 
TABELA 3

Correlação de Spearman entre as pontuações obtidas pelas crianças avaliadas nos dois instrumentos empregados $(\mathrm{N}=221)$

\begin{tabular}{lcccc}
\hline \multicolumn{1}{c}{ Instrumento } & RACF Som inicial & RACF Som final & RACF Som do meio & RACF \\
\hline PCFO - Síntese Silábica & 0,05 & $0,13^{*}$ & $0,16^{* *}$ & $0,16^{* *}$ \\
PCFO - Síntese Fonêmica & $0,29^{* *}$ & $0,39^{* *}$ & $0,37^{* *}$ & $0,47^{* *}$ \\
PCFO - Rima & $0,38^{* *}$ & $0,47^{* *}$ & $0,39^{* *}$ & $0,54^{* *}$ \\
PCFO - Aliteração & $0,37^{* *}$ & $0,44^{* *}$ & $0,32^{* *}$ & $0,48^{* *}$ \\
PCFO - Seg. Silábica & 0,09 & 0,11 & $0,19^{*}$ & $0,16^{*}$ \\
PCFO - Seg. Fonêmica & $0,25^{* *}$ & $0,28^{* *}$ & $0,24^{* *}$ & $0,35^{* *}$ \\
PCFO - Manip. Silábica & $0,35^{* *}$ & $0,35^{* *}$ & $0,33^{* *}$ & $0,43^{* *}$ \\
PCFO - Manip. Fonêmica & $0,35^{* *}$ & $0,36^{* *}$ & $0,35^{* *}$ & $0,48^{* *}$ \\
PCFO - Transp. Silábica & $0,26^{* *}$ & $0,31^{* *}$ & $0,22^{* *}$ & $0,33^{* *}$ \\
PCFO - Transp. Fonêmica & $0,19^{* *}$ & $0,43^{* *}$ & $0,37^{* *}$ & $0,44^{* *}$ \\
PCFO & $0,42^{* *}$ & $0,54^{* *}$ & $0,50^{* *}$ & $0,65^{* *}$ \\
\hline
\end{tabular}

$* \mathrm{p}<0,005 ; * * \mathrm{p}<0,001$.

Deve-se ressaltar que não foi encontrado um correspondente para o 'Som do meio' do Roteiro de Avaliação da Consciência Fonológica (RACF) na Prova de Consciência Fonológica por Produção Oral (PCFO). No entanto, os índices de correlação obtidos indicam que a rima e a aliteração são, respectivamente, os aspectos da consciência fonológica que os instrumentos avaliam com maior proximidade.

\section{DISCUSSÃO}

É sabido que a aprendizagem da leitura e da escrita e, de maneira mais ampla, a alfabetização se constitui num grande desafio do mundo moderno, no qual as notícias acerca do desempenho das crianças brasileiras em relação à aprendizagem de habilidades básicas, tais como, as citadas são desoladoras. Nesse sentido, considerando-se que as dificuldades com a consciência fonológica podem funcionar como um 'gargalo' que impede o desenvolvimento normal de outras habilidades, como, por exemplo, a leitura e a escrita, tal qual evidenciado por diversas pesquisas, estudos como o aqui apresentado se tornam ainda mais relevantes. Seu objetivo foi buscar por evidência de validade convergente entre o RACF, um instrumento que permite uma sondagem prévia e rápida para identificar eventuais dificuldades relativas a essa habilidade metalinguística, tendo como referência a PCFO.

Os resultados aqui obtidos indicaram que as pontuações médias superiores nos subtestes 'Síntese Silábica', 'Segmentação Silábica' e 'Aliteração' da PCFO, confirmaram os resultados obtidos anteriormente por autores como Capovilla e Capovilla (1998),
Barrera e Maluf (2003) e Capovilla et al. (2007). Ao lado disso, evidenciaram uma pontuação média em 'Rima' inferior à demonstrada em 'Aliteração', em ambos os instrumentos empregados, o que sugere que as crianças, do presente estudo, encontraram maior dificuldade em relação às manipulações que exigiam um trabalho relacionado às partes menores das palavras a elas apresentadas e, portanto, na manipulação de fonemas. Esses achados confirmam os obtidos, por exemplo, por Cardoso-Martins (1991), Antoniazzi et al. (2005), ao analisarem 45 crianças ingressantes na primeira série do ensino fundamental, e Capovilla et al. (2007) e reforçam a importância não apenas dessas habilidades, mas a necessidade de uma avaliação adequada das mesmas.

As análises referentes à correlação entre os instrumentos de avaliação da consciência fonológica empregados indicaram, de forma geral, uma correlação positiva e moderada (Dancey \& Reidy, 2006) entre eles. Isso indica que os desempenhos nos testes de consciência fonológica empregados avaliam partes comuns do mesmo construto. Vale destacar que o índice de correlação obtido entre as pontuações totais dos instrumentos foi excelente segundo os parâmetros de Prieto e Muñiz (2000). Dessa forma, é possível afirmar que esses resultados corroboram a expectativa inicial do presente estudo, uma vez que se esperava encontrar índices de correlação positiva e significativa entre os instrumentos e, portanto, evidências de validade convergente entre os mesmos.

O RACF oferece uma medida de rastreio adequada para uma avaliação inicial da consciência fonológica, sendo de fácil aplicação por ter um número reduzido 
de itens, permitindo a identificação de eventuais dificuldades, tal como indicam as evidências de validade constatadas. É possível afirmar que o instrumento é apropriado para uma avaliação inicial da consciência fonológica, pois avalia habilidades que a constituem, tais como: identificação do som inicial ou aliteração, do som intermediário e do som final ou rima das palavras. Essas habilidades são importantes não só porque são preditoras do progresso na aquisição da leitura e escrita, mas, especialmente, por serem adquiridas antes mesmo da criança ser exposta ao ensino formal da linguagem por meio de sua inserção na escola.

Assim, se a criança for avaliada com o RACF e apresentar dificuldades nessas habilidades que podem ser consideradas como preditoras, há um indicativo de que ela pode apresentar alguma dificuldade em relação à aprendizagem da leitura e escrita, especialmente durante a fase inicial do processo de escolarização. Em consequência, fica ressaltada a necessidade de uma avaliação mais pormenorizada da consciência fonológica incluindo-se, então, a aplicação de outros instrumentos e procedimentos de avaliação.

Há que se destacar ainda, que a avaliação de habilidades como a consciência fonológica com instrumentos com evidências de validade possibilita inferências confiáveis quanto aos desempenhos obtidos. Essa avaliação permite, também, que os professores tracem estratégias para sanar os problemas detectados. Com base nessas avaliações poderão ser implantados programas para o desenvolvimento de habilidades consideradas como insuficientes a serem aplicados na própria situação de sala de aula. É importante que os resultados que comprovam o impacto favorável de treinamentos de correspondências grafo-fonêmicas, bem como do ensino fônico de maneira geral, sejam incorporados às práticas pedagógicas da escola.

Os índices de correlação encontrados entre o som do meio do RACF e os subtestes de 'Síntese Fonêmica',
'Manipulação Fonêmica' e 'Transposição Fonêmica' do PCFO parecem indicar que há algo em comum em se dizer qual palavra apresenta o mesmo 'Som do meio' que a palavra modelo e unir seus fonemas, dizendo qual palavra resulta da união dos mesmos; adicionar e subtrair fonemas dizendo qual a palavra resultante, assim como falar a palavra ao contrário, invertendo cada um de seus sons. Logo, pode-se presumir que identificar o 'Som do meio' envolve habilidades mais refinadas do que as necessárias para a percepção do 'Som inicial e final', do mesmo modo que as habilidades fonêmicas exigem mais maturidade cognitiva por parte das crianças, conforme afirmado por vários estudiosos da área (Bernardino Jr. et al., 2006; Capovilla et al., 2007; Nascimento, 2006; para citar alguns), no entanto novos estudos para verificar essa relação são necessários.

Embora este estudo tenha fornecido evidências de validade para o RACF, confirmando a sua adequação para a avaliação da consciência fonológica é preciso que novas evidências de validade relativas à análise da estrutura interna dos itens, bem como evidências de validade de critério sejam investigadas de forma a ampliar o conhecimento sobre as suas características psicométricas. Espera-se, ainda, que a realização de outras pesquisas seja direcionada para superar as limitações deste estudo, utilizando amostras maiores, incluindo crianças provenientes de instituições de natureza jurídica diferentes e que tenham critérios de exclusão e inclusão mais bem definidos. Ao lado disso, tais estudos poderiam incluir medidas da inteligência a fim de esclarecer o papel mediador do processamento cognitivo. Ao considerar essas sugestões essas pesquisas poderão contribuir não apenas para a ampliação dos conhecimentos na área, mas, sobretudo, para o aprimoramento dos instrumentos e procedimentos técnicos empregados na avaliação psicológica para o contexto educacional.

\section{REFERÊNCIAS}

Antoniazzi, M. I. B., Suehiro, A. C. B., \& Santos, A. A. A. (2005). A relação entre a alfabetização e a consciência fonológica. In VII Congresso Nacional de Psicologia Escolar e Educacional. Curitiba-PR.

Babayigit, S. \& Stainthorp, R. (2011). Modeling the Relationships between Cognitive-Linguistic Skills and Literacy Skills: New Insights from a Transparent Orthography. Journal of Educational Psychology, 103(1), 169-189. http://dx.doi.org/10.1037/a0021671

Barrera, S. D. \& Maluf, M. R. (2003). Consciência metalingüística e alfabetização: um estudo com crianças da primeira série do ensino fundamental. Psicologia: Reflexão e Crítica, 16(3), 491-502. http://dx.doi.org/10.1590/s010279722003000300008

Bernardino Júnior, J. A., Freitas, F. R., Souza, D. G., Maranhe, E. A., \& Bandini, H. H. M. (2006). Aquisição de leitura e escrita como resultado do ensino de habilidades de consciência Fonológica. Revista Brasileira de Educação Especial, 12(3), 423-450. http://dx.doi.org/10.1590/S1413-65382006000300009 
Bradley, L, \& Bryant, P. (1983). Categorizing sounds and learning to read - a causal connection. Nature, 301, $419-521$. http://dx.doi.org/10.1038/301419a0

Capovilla, A. G. S., \& Capovilla, F. C. (1998). Prova de consciência fonológica: desenvolvimento de dez habilidades da pré-escola à segunda série. Temas sobre Desenvolvimento, 7(37), 14-20.

Capovilla, A. G. S., \& Capovilla, F. C. (2002). Otimizando a aquisição da linguagem escrita: comparação entre os métodos fônico e global de alfabetização. Cadernos de Psicopedagogia, 2(3), 68-97.

Capovilla, A. G. S., Capovilla, F. C., \& Soares, J. V. T. (2004). Consciência sintática no ensino fundamental: correlações com consciência fonológica, vocabulário, leitura e escrita. Psico-USF, 9(1), 39-47. http://dx.doi.org/10.1590/S141382712004000100006

Capovilla, A. G. S., Dias, N. M., \& Montiel, J. M. (2007). Desenvolvimento dos componentes da consciencia fonológica no ensino fundamental e correlação com nota escolar. Psico-USF, 12(1), 55-64.

Cardoso-Martins, C. (1991). A consciência fonológica e a aprendizagem inicial da leitura e da escrita. Cadernos de Pesquisa, (76), 41-49.

Cardoso-Martins, C. \& Frith, U. (1999). Consciência fonológica e habilidade de leitura na Síndrome de Down. Psicologia: Reflexão e Crítica, 12(1), 209-224. http://dx.doi.org/10.1590/s0102-79721999000100014

Cárnio, M. S. \& Santos, D. (2005). Phonological awareness improvement in primary school students. Pró-Fono Revista de Atualização Científica, 17(2), 195-200.

Correa, J. (2001). A aquisição do sistema de escrita por crianças. In J. Correa, A. G. Spinillo, \& S. Leitão (Orgs.), Desenvolvimento da linguagem escrita e textualidade (pp. 17-70). Rio de Janeiro: NAU: FAPERJ.

Corrêa, M. F. \& Cardoso-Martins, C. (2012). O Papel da Consciência Fonológica e da Nomeação Seriada Rápida na Alfabetização. Psicologia: Reflexão e Crítica, 25(4), 802-808. http://dx.doi.org/10.1590/s0102-79722012000400020

Cunha, V. L. O. \& Capellini, S. A. (2009). Desempenho de escolares de 1ํa a $4^{\mathrm{a}}$ série do ensino fundamental nas provas de habilidades metafonológicas e de leitura-PROHMELE. Revista Sociedade Brasileira Fonoaudiologia, 14(1), 5668. http://dx.doi.org/10.1590/S1516-80342009000100011

Dancey, C. P., \& Reidy, J. (2006). Análise de Correlação: o r de Pearson. In C. P. Dancey \& J. Reidy (Orgs.), Estatística sem Matemática para a Psicologia: usando SPSS para Windows (pp. 178-218). Porto Alegre: Artmed.

Dias, N. M. \& Bighetti, C. A. (2009). Intervenção em habilidades metafonológicas em estudantes do ensino fundamental e desenvolvimento de leitura. Psicologia em Revista, 15(3), 140-158.

Fukuda, M. T. M. \& Capellini, S. A. (2012). Programa de Intervenção Fonológica Associado à Correspondência Grafema-Fonema em Escolares de Risco para a Dislexia. Psicologia: Reflexão e Crítica, 25(4), 783-790. http://dx.doi. org/10.1590/s0102-79722012000400018

Godoy, D. M. A., Fortunato, N., \& Paiano, A. (2014). Panorama da última década de pesquisas com testes de consciência fonológica. Temas Psicologia, 22(2), 313-328. http://dx.doi.org/10.9788/TP2014.2-04

Goswami, U. \& Bryant, P. (1997). Phonological skills and learning to read. Hove, UK: Psychology Press Ltd.

Gough, P. B., Larson, K. C., \& Yopp, H. (1995). A estrutura da consciência fonológica. In C. Cardoso-Martins. Consciência fonológica e alfabetização (pp. 13-35). Petrópolis: Vozes.

Hagen, V., Miranda, L. C., \& Mota, M. M. P. E. (2010). Consciência morfológica: um panorama da produção científica em línguas alfabéticas. Psicologia: Teoria e Prática, 12(3), 135-148.

Justi, C. N. G. \& Roazzi, A. (2012). A Contribuição de Variáveis Cognitivas para a Leitura e a Escrita no Português Brasileiro. Psicologia: Reflexão e Crítica, 25(3), 605-614. http://dx.doi.org/10.1590/s0102-79722012000300021

Justi, C. N. G., Roazzi, A., \& Justi, F. R. R. (2014). São as tarefas de nomeação seriada rápida medidas do processamento fonológico? Psicologia: Reflexão e Crítica, 27(1), 44-54. http://dx.doi.org/10.1590/S0102-79722014000100006

Kim, Y. (2009). The foundation of literacy skills in Korean: the relationship between letter-name knowledge and phonological awareness and their relative contribution to literacy skills. Reading and Writing: An Interdisciplinary Journal, 22(8), 907-931. http://dx.doi.org/10.1007/s11145-008-9131-0

Landgraf, S., Beyer, R., Hild, I., Schneider, N., Horn, E., Schaadt, G., Foth, M., Pannekamp, A., \& Van Der Meer, E. (2012). Impact of phonological processing skills on written language acquisition in illiterate adults. Developmental Cognitive Neuroscience, 2(1), 129-138. http://dx.doi.org/10.1016/j.dcn.2011.11.006

Monteiro, S. M., \& Soares, M. (2014). Processos cognitivos na leitura inicial: relação entre estratégias de reconhecimento de palavras e alfabetização. Educação e Pesquisa, 40(2), 449-466. http://dx.doi.org/10.1590/S1517-97022014005000006

Mota, M. M. P. E., \& Guimarães, S. B. (2011). Leitura contextual e o processamento metalinguístico: considerações teóricas. Paidéia, 21(49), 279-283. http://dx.doi.org/10.1590/S0103-863X2011000200016

Mota, M. M. P. E., \& Santos, A. A. A. (2009). O papel da Consciência Fonológica na leitura contextual medida pelo teste de Cloze. Estudos de Psicologia-Natal, 14(3), 207-212. http://dx.doi.org/10.1590/S1413-294X2009000300004

Mota, M. M. P. E., Vieira, M. T., Bastos, R. R., Dias, J., Paiva, N., Mansur-Lisboa, S., \& Andrade-Silva, R. (2012). Leitura Contextual e Processamento Metalingüístico no Português do Brasil: Um Estudo Longitudinal. Psicologia: Reflexão e Crítica, 25(1), 114-120. http://dx.doi.org/10.1590/s0102-79722012000100014

Nascimento, L. C. R. (2006). Consciência Fonológica. [On-line]. Recuperado de <http://www.fonoesaude.org/ consfonologica.htm>. 
Novaes, C. B., Mishima, F., \& Santos, P. L. (2013). Treinamento breve de consciência fonológica: impacto sobre a alfabetização. Revista Psicopedagogia, 30(93), 189-200.

Paula, G. R., Mota, H. B., \& Keske-Soares, M. (2005). A terapia em consciência fonológica no processo de alfabetização. Pró-Fono Revista de Atualização Científica, 17(2), 175-184. http://dx.doi.org/10.1590/S0104-56872005000200006

Pedras, C. T. P. A., Geraldo, T., \& Crenitte, P. A. P. (2006). Consciência fonológica em crianças de escola pública e particular. Revista da Sociedade Brasileira de Fonoaudiologia, 11(2), 65-69.

Pedro, C., Oliveira, T., Lousada, M., \& Couto, P. S. (2014). Estudo sobre a intervenção em crianças falantes do Português Europeu com atraso fonológico. DELTA, 30(1), 61-93. http://dx.doi.org/10.1590/S0102-44502014000100005

Pestun, M. S. V. (2005). Consciência fonológica no início da escolarização e o desempenho ulterior em leitura e escrita: estudo correlacional. Estudos de Psicologia, 10(3), 407-412. http://dx.doi.org/10.1590/S1413-294X2005000300009

Pestun, M. S. V., Omote, L. C. F., Barreto, D. C. M., \& Matsuo, T. (2010). Estimulação da consciência fonológica na educação infantil: prevenção de dificuldades na escrita. Psicologia Escolar e Educacional, 14(1), 95-104. http://dx.doi. org/10.1590/S1413-85572010000100011

Phillips, B. M., Clancy-Manchetti, J., \& Lonigan, C. J. (2008). Successful phonological awareness instruction with preschool children. Topic in Early Childwood Special Education, 28(1), 3-17. http://dx.doi.org/10.1177/0271121407313813

Prieto, G. \& Muñiz, J. (2000). Un modelo para evaluar la calidad de los testes utilizados en España. Papeles del Psicólogo, 77, 65-75.

Roazzi, A. (1990). Explicações causais em desenvolvimento cognitivo: a relação consciência fonológica e leitura. In III Simpósio Brasileiro de Pesquisa e Intercâmbio Científico (pp. 14-26). Águas de São Pedro, SP: ANPEPP.

Roazzi, A., \& Dowker, A. (1989). Consciência fonológica, rima e aprendizagem da leitura. Psicologia: Teoria e Pesquisa, 5(1), 31-55.

Roazzi, A., \& Oliveira, G. G. (1994). As habilidades lingüísticas dos repentistas e sua relação com o nível de consciência fonológica. Cadernos de Estudos Linguísticos, (26), 135-158.

Salgado, C., \& Capellini, S. A. (2004). Desempenho em leitura e escrita de escolares com transtorno fonológico. Psicologia Escolar e Educacional, 8(2), 179-188. http://dx.doi.org/10.1590/S1413-85572004000200006

Santos, A. A. A. (1996). A influência da consciência fonológica na aquisição da leitura e da escrita. In F. F. Sisto, G. C. Oliveira, L. D. T. Fini, M. T. C. C. Souza, \& R. P. Brenelli (Orgs.), Atuação psicopedagógica e aprendizagem escolar (pp. 213-247). Petrópolis: Vozes.

Shaywitz, S. (2006). Entendendo a dislexia: um novo e completo programa para todos os niveis de problemas de leitura. Porto Alegre: Artmed.

Suehiro, A. C. S., \& Santos, A. A. A. (2011). Roteiro de Avaliação da Consciência Fonológica (RACF). Acta Colombiana de Psicología, 14(1), 147-154.

Suehiro, A. C. S., \& Santos, A. A. A. (2011). Roteiro de Avaliação da Consciência Fonológica (RACF). Acta Colombiana de Psicología, 14(1), 147-154.

Torgesen, J. K., Wagner, R. K., \& Rashotte, C. A. (1994). Longitudinal of phonological procesing and reading. Journal of Learning Disabilities, 27(5), 276-286. http://dx.doi.org/10.1177/002221949402700503

Urbina, S. (2007). Fundamentos da testagem psicológica. Porto Alegre-RS: Artmed.

Yopp, H. K. (1988). The validity and reliability of phonemic awareness tests. Reading Research Quarterly, 23(2), 159177.http://dx.doi.org/10.2307/747800

\footnotetext{
Autores: Recôncavo da Bahia - Santo Antônio de Jesus.

\author{
Endereço para correspondência: \\ Adriana Cristina Boulhoça Suehiro \\ Rua Rosalvo Fonseca, 225 - São Cristóvão \\ CEP 44571-037 Santo Antônio de Jesus, BA, Brasil \\ E-mail: dricbs@yahoo.com.br
}

Adriana Cristina Boulhoça Suehiro - Psicóloga. Doutora em Psicologia pelo Programa de Pós-Graduação Stricto Sensu em Psicologia da Universidade São Francisco, pós-doutoramento em Educação pela Faculdade de Educação da UNICAMP e docente da Universidade Federal do

ACÁCIA APARECIDA ANGeli dos SANTOS - Psicóloga. Doutora em Psicologia Escolar e Desenvolvimento Humano pela USP e Docente da Graduação e do Programa de Pós-Graduação Stricto Sensu em Psicologia da Universidade São Francisco/Itatiba. Bolsista produtividade do CNPq.

Recebido em: 19.08 .15

Aceito em: 05.10 .15 